\title{
(Research Article) \\ Design, Analysis, and Optimization of Column and Headstock of Moveable Column Vertical Machining Center
}

\author{
J. J. Vaghela ${ }^{1^{*}}$, R. R. Trivedi ${ }^{2}$, V. Zala ${ }^{3}$ \\ ${ }^{1 *}$ Department of M Engineering, Darshan Institute of Engineering \& Technology Rajkot, Gujarat, INDIA \\ ${ }^{2}$ Department of Mechanical Engineering, Nirma University, Ahmedabad, Gujarat, INDIA \\ ${ }^{3}$ Department of Research \& Development, Jyoti CNC Automation Ltd., Rajkot, Gujarat, INDIA
}

\begin{abstract}
This paper deals with the design and development of a moveable column Vertical Machining Centre. In the current scenario, most of the Vertical Machining Centers have a stationary column. It is a need for industries to develop VMC machines with movable column. The present work proposes the conceptual design of headstock and column of VMC machines with the movable column as the conventional VMC machines with fix column has certain issues like maintenance problem, work proficiency, smaller working span, bulky construction, etc. The objective of this paper is to create the best possible design of movable column and headstock of the VMC machine such that higher stiffness can be achieved. It is done by carrying out structural analysis and by applying various optimization techniques like shape, size, and mass optimization. A model of the headstock of the movable column $V M C$ is presented. The headstock and column are designed using the reference of an in-house developed machine. The stiffness values, deformation values, stress values, frequency response at any point of the body can be determined. The shape and size are optimized without negotiating the allowable stiffness values of the structure. Mass is optimized insignificant amount keeping deformation in permissible values.
\end{abstract}

Keywords: Moveable column VMC, Stiffness, Structural analysis, Size optimization, Shape optimization, Mass optimization.

\section{Introduction}

A vertical machining center is a large-scale computerized numerical control machine in which the spindle, or cutting element, is aligned vertically (up and down). High-end VMCs are high-precision machines often used for tight-tolerance millings, such as fine die and mold work. Low-cost vertical machining centers are among the most basic CNC machine tools. A low-cost VMC is often a new machine shop's first machine tool purchase. In the world of CNC machining, the vertical machining center has grown to become the leading piece of machining equipment used in machine shops. The vertical machining centers have proven to be more versatile for industrial manufacturing applications than the equivalent horizontal centers.

Starting with the humble drill press and continuing through to computer-automated machining today, the vertical machining center is simply the most economical and effective way to machine metal, stone, or other substances. The primary

${ }^{*}$ Corresponding Author: e-mail: jigar.vaghela@darshan.ac.in, Tel-+91-8866110641

ISSN 2320-7590

(C) 2020 Darshan Institute of Engg. \& Tech., All rights reserved advantage is that gravity is working with you rather than trying to fight against it.

In the current scenario, most of the VMC machines have a stationary column. The objective of this work is to develop a VMC machine with a movable column and corresponding to that column, headstock modification. It is a new concept that can replace conventional VMC machines because there are certain issues with an existing design like maintenance problems, work proficiency, smaller working span, bulky construction, etc.

In the first stage, the design of the headstock has been carried out. For the standard dimensions of the head, the stock is taken initially. After that, the headstock has been analyzed by applying loading conditions and boundary conditions. With that analysis deformation and stress, values have been defined. Then shape, size, and mass optimization are performed by limiting deformation values. Hence when the final dimensions of the headstock will achieve, we can move to the column part. We have to repeat the same procedure for designing the column. After finishing the design of the column, we need to study the dynamic behavior of the whole assembly and have to do modifications accordingly. 


\section{Preface}

The primary specification for the project machine is as given below, which is necessary for the design procedure. The data of the machine is provided by Jyoti CNC Automation, Ltd., Rajkot.

\subsection{Vertical Machining Center:}

- Type: Moveable column VMC

- Axes travel

- Travel in X-Direction: 500-1000 mm

- Travel in Y-Direction: $500 \mathrm{~mm}$

- Travel in Z-Direction: $500 \mathrm{~mm}$

- Spindle specifications

- Spindle type: BT40 (Built-in motor spindle)

- Spindle power: $10 \mathrm{KW}$

- Spindle speed: $12000 \mathrm{rpm}$

- Spindle Weight: $120 \mathrm{Kg}$

- Spindle Diameter: $230 \mathrm{~mm}$

\subsection{Load due to drilling in the vertical direction [1][2][3]}

$$
F=\frac{\left\{K^{\prime} * K c * f * d\right\}}{2}
$$

$\mathrm{Kc}$ - specific cutting force $\left(\mathrm{N} / \mathrm{mm}^{2}\right)$, which depends primarily on the material being machined

$\mathrm{f}$ - feed per rotation $(\mathrm{mm})$

$\mathrm{d}$ - Tool diameter $(\mathrm{mm})$

K' - Coefficient that depends on the geometry of the tip of the tool (we can consider an average value of 0.5) For the standard drilling process in VMC

So,

$\mathrm{F}=3347 \mathrm{~N}$ so approximately $3000 \mathrm{~N}$

Let's design for $5000 \mathrm{~N}$ including FOS.

\subsection{Load due to milling in the horizontal direction [1][2][3]}

$$
F=\frac{\left\{H C P^{\prime} * E * 33000\right\}}{n}
$$

$\mathrm{HCP}-$ Heaviest cut horsepower

E - Machine efficiency

$\mathrm{n}$ - Cutting speed

Heaviest-cut horsepower is not total machine horsepower, rather it is the maximum horsepower actually used during the machining cycle.

Typical machine efficiency is roughly $75 \%$ (.75). [4]

The number 33,000 is a unit-conversion factor.

So,

Cutting force $=3298$ Newton

Taking $3000 \mathrm{~N}$ roughly for the design.

We have used Gray cast iron, grade-25 (GC-25) [7] as the material because of its casting characteristics and superior properties that are highly for structural elements of machine tools.

\section{Design of headstock}

The solid model of the equipment is used for evaluation. The geometric modeling of the equipment is done in Creo-2.0 software. The analysis software used is Ansys Version 14. The model generated in the Creo is transferred to Ansys Design Modeler, as a Para solid, for Analysis and further process. Material Properties are defined in Ansys Engineering Data. The Meshing, application of the load, and boundary conditions are done in Ansys Mechanical. Ansys Workbench is used for solving the model and the results viewing.

Table 1. Modeling data for the headstock

\begin{tabular}{|c|c|}
\hline Length of the headstock & $700 \mathrm{~mm}$ \\
\hline Height of the headstock & $550 \mathrm{~mm}(\mathrm{P})$ \\
\hline Width of the headstock & $550 \mathrm{~mm}(\mathrm{P})$ \\
\hline Thickness & $10 \mathrm{~mm}$ \\
\hline Spindle diameter & $230 \mathrm{~mm}$ \\
\hline Height of tool and tool post assembly & $160 \mathrm{~mm}$ \\
\hline \multicolumn{2}{|c|}{ Tetrahedral elements are used for meshing the structure. } \\
\hline
\end{tabular}

To understand the deflection and stress behavior of the component, we will make four iterations with a different type of load settings.[6]

- Only drilling force in $-Y$ direction

- Only milling force in $-X$ direction

- Only milling force in $-Z$ direction

- Combine forces, drilling force in $-Y \&$ milling force in $-\mathrm{X}$ direction

For deciding the size of the object, we have to do some iterations with different dimensions.

Table 2. Table of design points

\begin{tabular}{|c|c|c|c|c|}
\hline & Name & Height & Width & Plane: W/2 \\
\hline 1 & DP 0 & 550 & 550 & 275 \\
\hline 2 & DP 1 & 575 & 550 & 275 \\
\hline 3 & DP 2 & 600 & 550 & 275 \\
\hline 4 & DP 3 & 650 & 550 & 275 \\
\hline 5 & DP 4 & 525 & 550 & 275 \\
\hline 6 & DP 5 & 500 & 550 & 275 \\
\hline 7 & DP 6 & 475 & 550 & 275 \\
\hline 8 & DP 7 & 450 & 550 & 275 \\
\hline 9 & DP 8 & 550 & 600 & 300 \\
\hline 10 & DP 9 & 550 & 650 & 325 \\
\hline 11 & DP 10 & 550 & 500 & 250 \\
\hline 12 & DP 11 & 550 & 450 & 225 \\
\hline
\end{tabular}

These dimensions are taken randomly to choose the optimum design required to sustain the loads. A set of loads calculated earlier are implemented on all design points and results are as follows. 


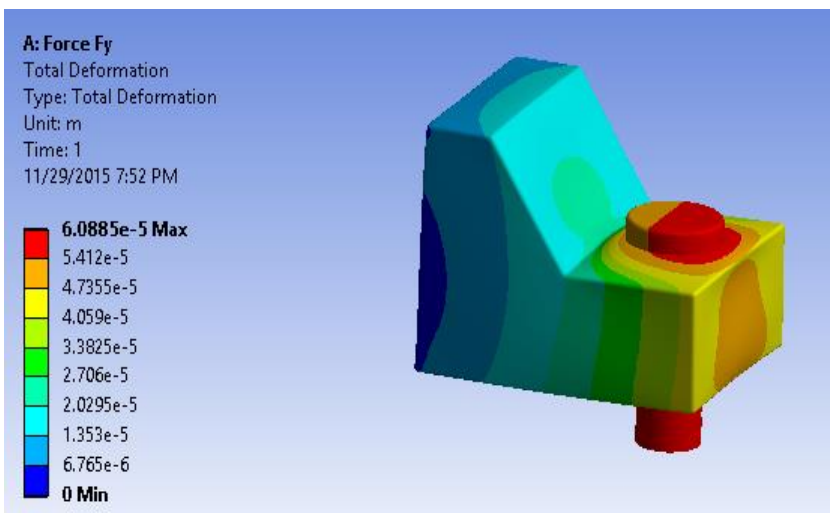

Figure 1. Deformation due to drilling force exerted in $-\mathrm{Y}$

Table 3. Results for drilling force in $-\mathrm{Y}$

\begin{tabular}{|c|c|c|c|}
\hline & Name & $\begin{array}{c}\text { Total Deformation } \\
(\mathrm{m}) * 10^{-5}\end{array}$ & Mass $(\mathrm{Kg})$ \\
\hline 1 & DP 0 & 6.08 & 244.44 \\
\hline 2 & DP 1 & 5.7 & 248.92 \\
\hline 3 & DP 2 & 6.93 & 253.27 \\
\hline 4 & DP 3 & 6.26 & 262.09 \\
\hline 5 & DP 4 & 6.46 & 240.03 \\
\hline 6 & DP 5 & 7.07 & 235.62 \\
\hline 7 & DP 6 & 7.74 & 231.2 \\
\hline 8 & DP 7 & 8.87 & 226.79 \\
\hline 9 & DP 8 & 6.06 & 252.78 \\
\hline 10 & DP 9 & 6.06 & 261.12 \\
\hline 11 & DP 10 & 5.92 & 236.1 \\
\hline 12 & DP 11 & 5.7 & 227.77 \\
\hline
\end{tabular}

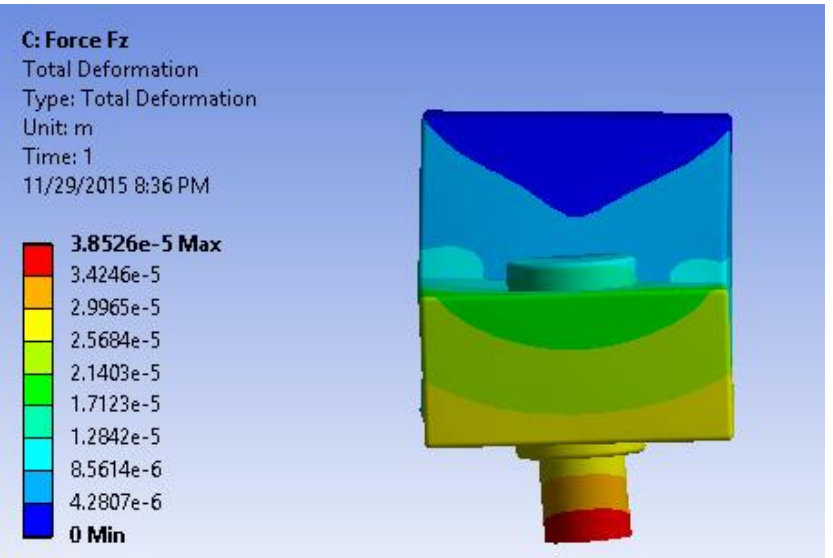

Figure 2. Deformation due to milling force exerted in $-\mathrm{Z}$

Table 4. Results for milling force in $-\mathrm{Z}$

\begin{tabular}{|c|c|c|c|}
\hline & Name & $\begin{array}{c}\text { Total Deformation } \\
(\mathrm{m}) * 10^{-5}\end{array}$ & Mass $(\mathrm{Kg})$ \\
\hline 1 & DP 0 & 3.83 & 244.44 \\
\hline 2 & DP 1 & 3.51 & 248.92 \\
\hline 3 & DP 2 & 5.54 & 253.27 \\
\hline 4 & DP 3 & 5.44 & 262.09 \\
\hline 5 & DP 4 & 4.25 & 240.03 \\
\hline
\end{tabular}

\begin{tabular}{|c|c|c|c|}
\hline 6 & DP 5 & 5.85 & 235.62 \\
\hline 7 & DP 6 & 5.64 & 231.2 \\
\hline 8 & DP 7 & 6.80 & 226.79 \\
\hline 9 & DP 8 & 3.43 & 252.78 \\
\hline 10 & DP 9 & 3.10 & 261.12 \\
\hline 11 & DP 10 & 4.35 & 236.1 \\
\hline 12 & DP 11 & 4.94 & 227.77 \\
\hline
\end{tabular}

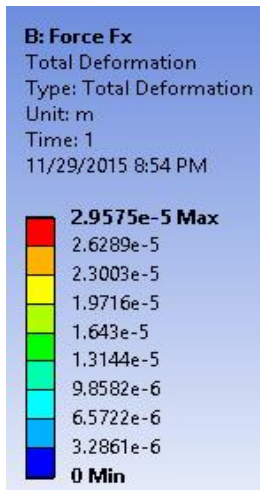

Figure 3. Deformation due to milling force exerted in $X$

Table 5. Results for milling force in $X$

\begin{tabular}{|c|c|c|c|}
\hline & Name & $\begin{array}{c}\text { Total Deformation } \\
(\mathrm{m}) * 10^{-5}\end{array}$ & Mass (Kg) \\
\hline 1 & DP 0 & 2.95 & 244.44 \\
\hline 2 & DP 1 & 2.94 & 248.92 \\
\hline 3 & DP 2 & 24.74 & 253.27 \\
\hline 4 & DP 3 & 23.49 & 262.09 \\
\hline 5 & DP 4 & 3.57 & 240.03 \\
\hline 6 & DP 5 & 4.44 & 235.62 \\
\hline 7 & DP 6 & 5.63 & 231.2 \\
\hline 8 & DP 7 & 7.45 & 226.79 \\
\hline 9 & DP 8 & 2.95 & 252.78 \\
\hline 10 & DP 9 & 2.96 & 261.12 \\
\hline 11 & DP 10 & 2.93 & 236.1 \\
\hline 12 & DP 11 & 2.92 & 227.77 \\
\hline
\end{tabular}

Goal-driven optimization of Ansys workbench is used to get the most suitable dimensions of the headstock. The width and height of the component are optimized. We cannot vary the length because of geometrical restrictions. From the given design points, the software automatically generates the design of experiments and extreme limits for the particular dimension.

Table 6. Optimization points choose by ANSYS

\begin{tabular}{|c|c|c|c|}
\hline & Name & Height & Width \\
\hline 1 & DP 1 & 550 & 550 \\
\hline 2 & DP 2 & 495 & 550 \\
\hline 3 & DP 3 & 605 & 550 \\
\hline 4 & DP 4 & 550 & 605 \\
\hline 5 & DP 5 & 550 & 550 \\
\hline 6 & DP 6 & 550 & 550 \\
\hline
\end{tabular}




\begin{tabular}{|c|c|c|c|}
\hline 7 & DP 7 & 550 & 550 \\
\hline 8 & DP 8 & 505.28 & 505.28 \\
\hline 9 & DP 9 & 594.72 & 505.28 \\
\hline 10 & DP 10 & 505.28 & 594.72 \\
\hline 11 & DP 11 & 594.72 & 594.72 \\
\hline 12 & DP 12 & 505.28 & 505.28 \\
\hline 13 & DP 13 & 594.72 & 505.28 \\
\hline 14 & DP 14 & 505.28 & 594.72 \\
\hline 15 & DP 15 & 594.72 & 594.72 \\
\hline
\end{tabular}

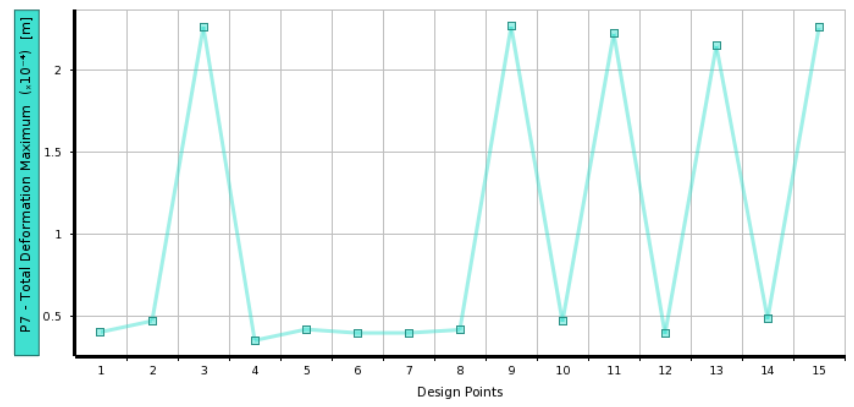

Figure 4. Deformation at different design points

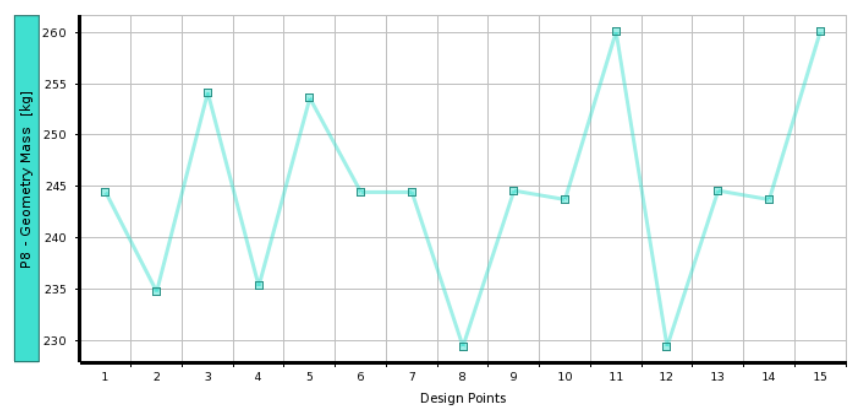

Figure 5. Mass at different design points

Here we can see that deformation at design point 4 is minimum.

- $\quad$ Design point 4

- Height $=550 \mathrm{~mm}, \mathrm{Width}=495 \mathrm{~mm}$

Mass is minimum at design point 8.

- Design point 8

- Height $=505.28 \mathrm{~mm}$, Width $=505.28 \mathrm{~mm}$

Now we have to tread off the values of mass and deformation in such a way that maximum deformation remains within the limit but total mass can be significantly reduced. Along with that we also have to optimize the dimensions of height and width for the minimum deformation.

Here as given in Table no. 7 deformation value of point A is very high so we cannot select it. To make a selection between A \& B, we prioritized mass because of not much variation in deformation.

So, selecting point $\mathrm{B}$ as the design point.

Height $=510.9 \mathrm{~mm}$ taking $510 \mathrm{~mm}$ approx.
Width $=498.9 \mathrm{~mm}$ taking $500 \mathrm{~mm}$ approx.

For this dimensions Deformation $=37$ micron

- Mass is reduced by $6 \%$ off the initial value.

- Height reduced by $7 \%$ and width is reduced by $9 \%$ from the initial values.

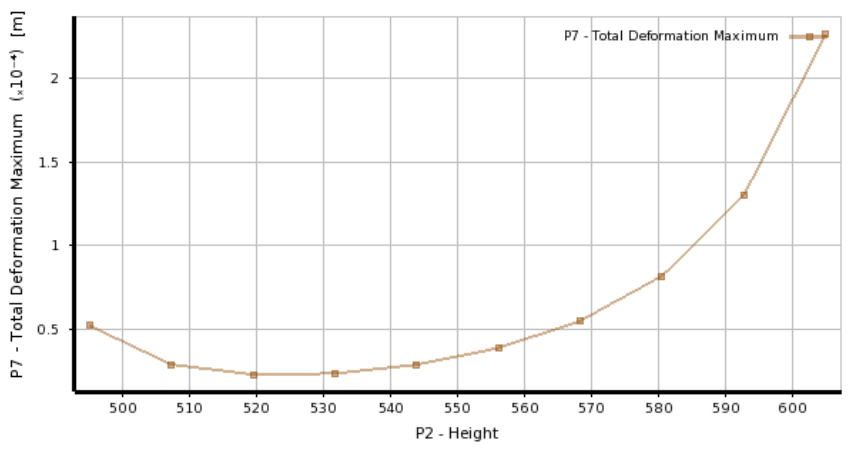

Figure 6. Deformation at different heights

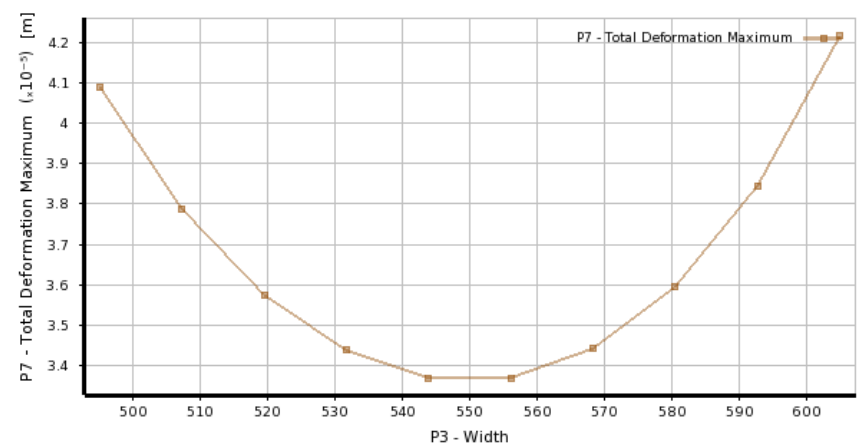

Figure 7. Deformation at widths

Table 7. Optimized candidate points

\begin{tabular}{|c|c|c|c|c|c|}
\hline & Height & Width & $\begin{array}{c}\text { Stress } \\
(\mathrm{Pa})\end{array}$ & $\begin{array}{c}\text { Defor. } \\
(\mathrm{m})\end{array}$ & $\begin{array}{c}\text { Mass } \\
(\mathrm{Kg})\end{array}$ \\
\hline & 495,605 & 495,605 & & & \\
\hline Obj. & Minimize & Minimize & Minimize & Minimize & Minimize \\
\hline Can. & & & & & \\
\hline \multirow{2}{*}{ A } & $\star \star \star$ & $\star \star$ & $\star \star$ & $\star \star$ & $\star \star \star$ \\
\cline { 2 - 6 } & 495.06 & 495.06 & $8.04 \mathrm{E} 06$ & $8.55 \mathrm{E}-05$ & 226.02 \\
\hline \multirow{2}{*}{ B } & $\star \star$ & $\star \star \star$ & $\star \star \star$ & $\star \star \star$ & $\star \star$ \\
\cline { 2 - 7 } & 510.9 & 498.92 & $6.07 \mathrm{E} 06$ & $8.76 \mathrm{E}-05$ & 229.31 \\
\hline \multirow{2}{*}{ C } & $\star \star$ & $\star$ & $\star \star \star$ & $\star \star \star$ & $\star \star$ \\
\cline { 2 - 7 } & 512.88 & 524.7 & $5.88 \mathrm{E} 06$ & $8.35 \mathrm{E}-05$ & 233.81 \\
\hline
\end{tabular}

\section{Design of Column}

Table 8. Modeling data for Column

\begin{tabular}{|c|c|}
\hline Length of the headstock & $700 \mathrm{~mm}$ \\
\hline Height of the headstock & $510 \mathrm{~mm}$ \\
\hline Width of the headstock & $500 \mathrm{~mm}$ \\
\hline Sheet thickness of the headstock & $12 \mathrm{~mm}$ \\
\hline Spindle diameter & $230 \mathrm{~mm}$ \\
\hline Spindle height & $350 \mathrm{~mm}$ \\
\hline Height of tool and tool post assembly & $150 \mathrm{~mm}$ \\
\hline Length of the column & $550 \mathrm{~mm} \mathrm{(P)}$ \\
\hline
\end{tabular}




\begin{tabular}{|c|c|}
\hline Height of the column & $1050 \mathrm{~mm}$ \\
\hline Width of the column & $500 \mathrm{~mm}$ \\
\hline Sheet thickness of the column & $15 \mathrm{~mm}$ \\
\hline
\end{tabular}

The mass of the created model with this dimension is 849.95 $\mathrm{Kg}$. The reference data is provided by Jyoti CNC Automation Ltd.

Tetrahedral and brick elements are used for meshing the structure[8]. The element is defined by 8 nodes having three degrees of freedom per node: translations in the nodal $x, y$, and $\mathrm{z}$ directions. For deciding the size of the object, we have to do some iterations with different dimensions. So, we can get the minimum of components for the allowable limit of deflection. Here we cannot vary the width and height of the column, so keeping it constant. The length of the column can be varied according to the suitability of the design.

Table 9. Table of design points

\begin{tabular}{|c|c|c|}
\hline & Name & Length \\
\hline 1 & DP 0 & 500 \\
\hline 2 & DP 1 & 550 \\
\hline 3 & DP 2 & 600 \\
\hline 4 & DP 3 & 450 \\
\hline
\end{tabular}

To understand the deflection and stress behavior of the component, we will make four iterations with a different type of load setting same as headstock [6].

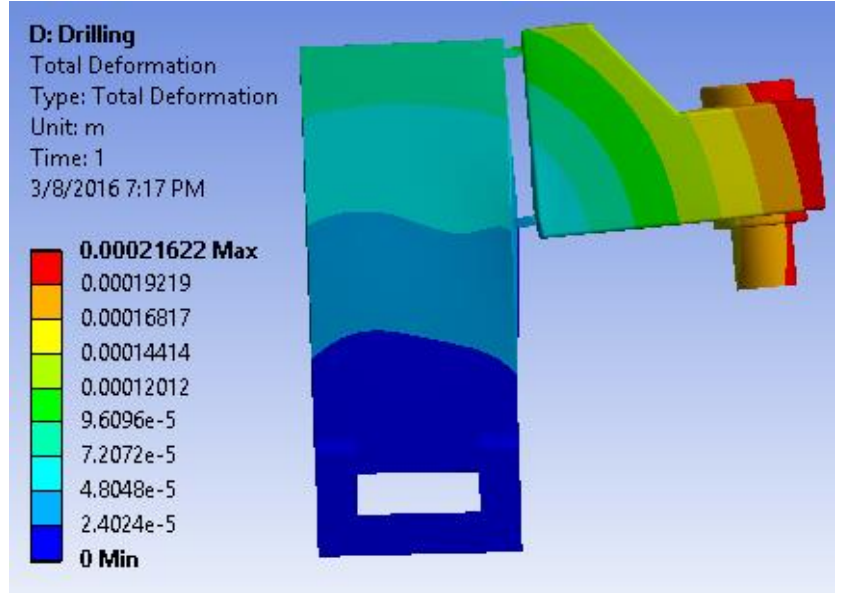

Figure 8. Deformation due to drilling force exerted in $-\mathrm{Y}$

Table 10. Results for drilling force in $-Y$

\begin{tabular}{|c|c|c|c|}
\hline & Name & Length & $\begin{array}{c}\text { Total } \\
\text { Deformation(m) }\end{array}$ \\
\hline 1 & DP 0 & 500 & 0.0002162 \\
\hline 2 & DP 1 & 550 & 0.0002503 \\
\hline 3 & DP 2 & 600 & 0.0002495 \\
\hline 4 & DP 3 & 450 & 0.0002184 \\
\hline
\end{tabular}

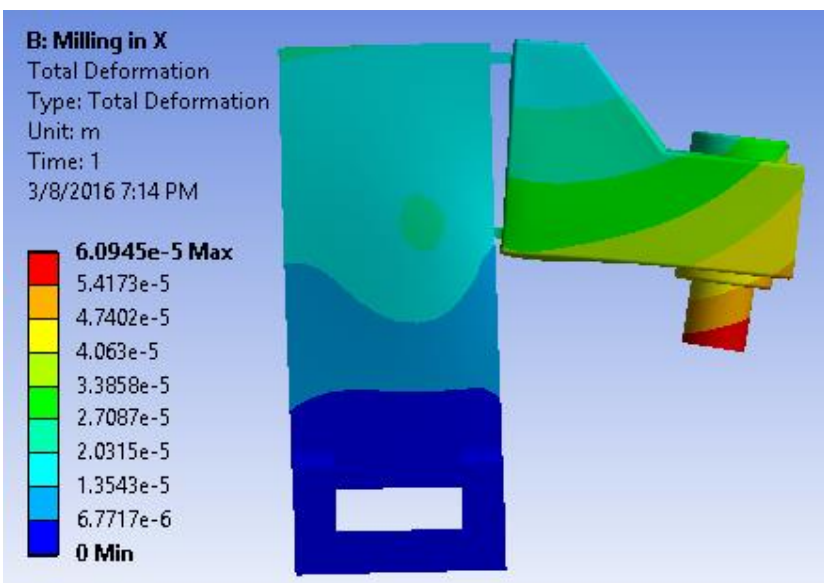

Figure 9. Deformation due to milling force exerted in $\mathrm{X}$

Table 11. Results for milling force in $X$

\begin{tabular}{|c|c|c|c|}
\hline & Name & Length & $\begin{array}{c}\text { Total } \\
\text { Deformation(m) }\end{array}$ \\
\hline 1 & DP 0 & 500 & $6.09 \mathrm{E}-05$ \\
\hline 2 & DP 1 & 550 & $6.06 \mathrm{E}-05$ \\
\hline 3 & DP 2 & 600 & $5.99 \mathrm{E}-05$ \\
\hline 4 & DP 3 & 450 & $6.18 \mathrm{E}-05$ \\
\hline
\end{tabular}

\section{C: Milling in Z}

Total Deformation

Type: Total Deformation

Unit: $m$

Time: 1

3/8/2016 7:15 PM

\subsection{Max}

0.00010744

$9.4006 \mathrm{e}-5$

$8.0577 \mathrm{e}-5$

$6.7147 \mathrm{e}-5$

$5.3718 \mathrm{e}-5$

$4.0288 \mathrm{e}-5$

$2.6859 \mathrm{e}-5$

$1.3429 \mathrm{e}-5$

0 Min

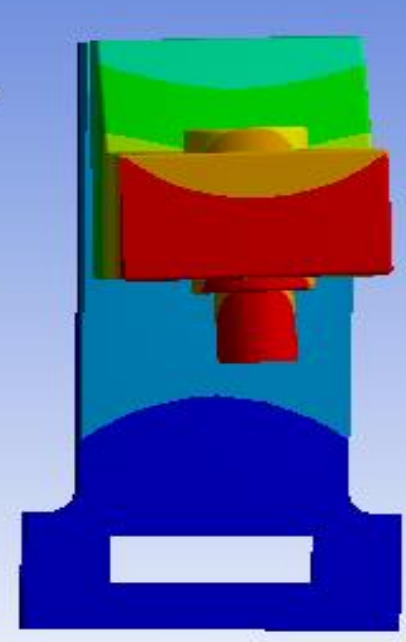

Figure 10. Deformation due to milling force exerted in $\mathrm{Z}$

Table 12. Results for milling force in $\mathrm{Z}$

\begin{tabular}{|c|c|c|c|}
\hline & Name & Length & $\begin{array}{c}\text { Total } \\
\text { Deformation(m) }\end{array}$ \\
\hline 1 & DP 0 & 500 & 0.0001208 \\
\hline 2 & DP 1 & 550 & 0.0001242 \\
\hline 3 & DP 2 & 600 & 0.0001260 \\
\hline 4 & DP 3 & 450 & 0.0001199 \\
\hline
\end{tabular}


To obtain proper design and to make design for maximum loading, let's check the deformation in case of combined loading.

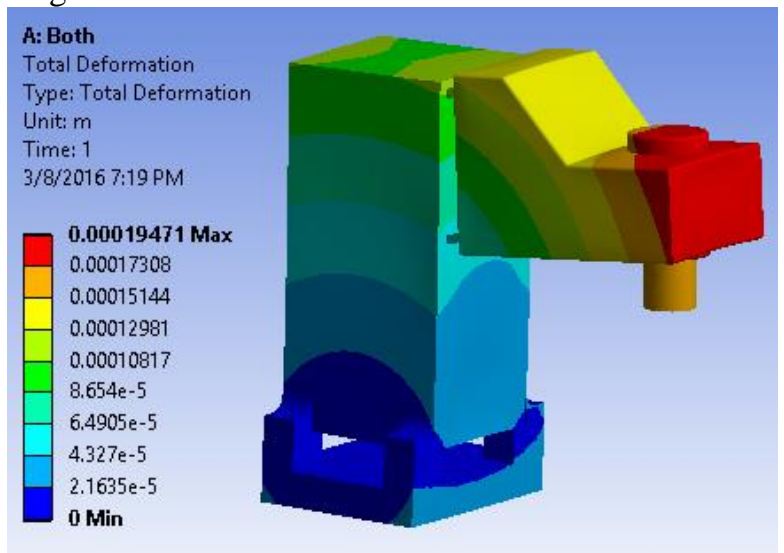

Figure 11. Deformation due combine loading

Table 13. Results for milling combine forces

\begin{tabular}{|c|c|c|c|c|}
\hline & Name & Length & $\begin{array}{c}\text { Total } \\
\text { Deformation(m) }\end{array}$ & $\begin{array}{c}\text { Mass } \\
(\mathrm{Kg})\end{array}$ \\
\hline 1 & DP 0 & 500 & 0.0001947 & 833.53 \\
\hline 2 & DP 1 & 550 & 0.0002372 & 849.95 \\
\hline 3 & DP 2 & 600 & 0.0002353 & 866.36 \\
\hline 4 & DP 3 & 450 & 0.0001970 & 817.12 \\
\hline
\end{tabular}

Table 14. Optimization points choose by ANSYS

\begin{tabular}{|c|c|c|c|c|}
\hline & Name & Length & $\begin{array}{c}\text { Total } \\
\text { Deformation(m) }\end{array}$ & $\begin{array}{c}\text { Mass } \\
(\mathrm{Kg})\end{array}$ \\
\hline 1 & DP 1 & 500 & 0.0001947 & 833.53 \\
\hline 2 & DP 2 & 450 & 0.0001970 & 817.12 \\
\hline 3 & DP 3 & 550 & 0.0002372 & 849.95 \\
\hline 4 & DP 4 & 475 & 0.0001942 & 825.32 \\
\hline 5 & DP 5 & 525 & 0.0002112 & 841.74 \\
\hline
\end{tabular}

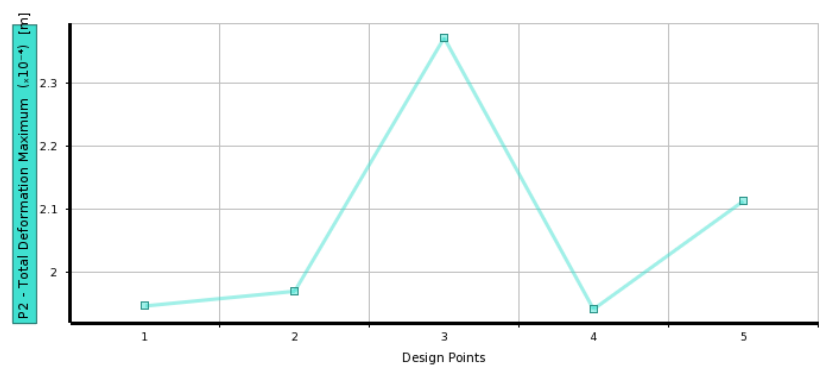

Figure 12. Deformation at different design points

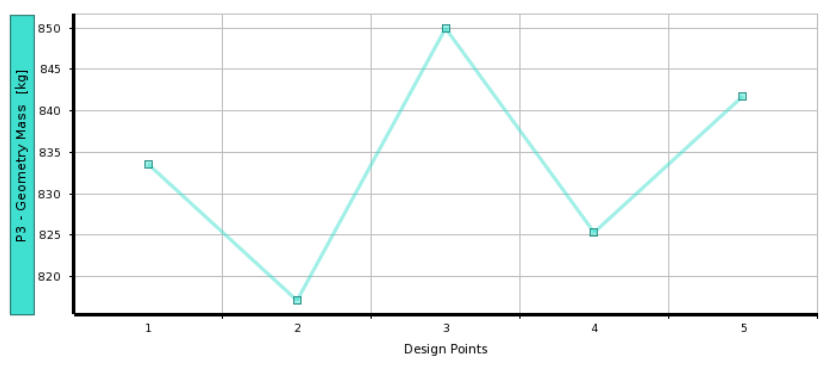

Figure 13. Mass at different design points
Here we can see that deformation at design point 4 is minimum.

- $\quad$ Design point 4

- $\quad$ Length $=475 \mathrm{~mm}$

Mass is minimum at design point 8 .

- $\quad$ Design point 8

- Length $=450 \mathrm{~mm}$

So, we have to tread off the values of mass and deformation in such a way that maximum deformation remains within the limit but total mass can be significantly reduced. Along with that we also have to optimize the dimension of length for the minimum deformation.

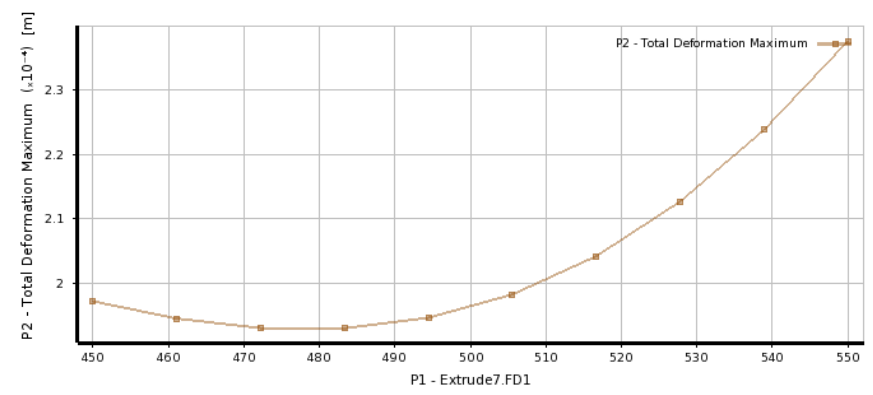

Figure 14. Deformation at different lengths

Table 15. Optimized candidate points

\begin{tabular}{|c|c|c|c|}
\hline & Length & $\begin{array}{c}\text { Deformation. } \\
(\mathrm{m})\end{array}$ & $\begin{array}{c}\text { Mass } \\
(\mathrm{Kg})\end{array}$ \\
\hline & 495,605 & & \\
\hline Obj. & Minimize & Minimize & Minimize \\
\hline Can. & & & \\
\hline \multirow{2}{*}{ A } & $\star \star \star$ & $\star \star$ & $\star \star$ \\
\cline { 2 - 4 } & 450.05 & 0.0001973 & 817.13 \\
\hline \multirow{2}{*}{ B } & $\star \star$ & $\star \star \star$ & $\star \star$ \\
\cline { 2 - 4 } & 560.05 & 0.0001948 & 820.42 \\
\hline \multirow{2}{*}{ C } & $\star \star \star$ & $\star \star \star$ & \\
\cline { 2 - 4 } & 470.05 & 0.0001933 & 823.7 \\
\hline
\end{tabular}

After trading off all the parameters, we get the 3 most suitable candidates and after comparing this result with the individual loading conditions. we need to select a value that is optimum for all four cases which are around 485-495 $\mathrm{mm}$.

So tacking $500 \mathrm{~mm}$ as a design length. At $500 \mathrm{~mm}$ length mass of the structure is $833.53 \mathrm{Kg}$.

- Optimized mass $16 \mathrm{~kg}$ approx.

- Optimized size Length $50 \mathrm{~mm}$.

\section{Ribbing structure}

Ribs are a very important part of any structure. They are required to support structure against various failures and to provide extra stiffness to them.

After finalizing the dimensions of the headstock and column, our next task is to provide ribs to them.

To decide ribbing structure, we've referred to N. K. Mehta and some other machine tool structure related books [4][3][1][10] and some handbooks. Let's see the stiffener arrangement for our structure and its effect on the stiffness of the system. After 
providing ribs we can we need to analyze the structure with the same loading and boundary condition to compare the results.

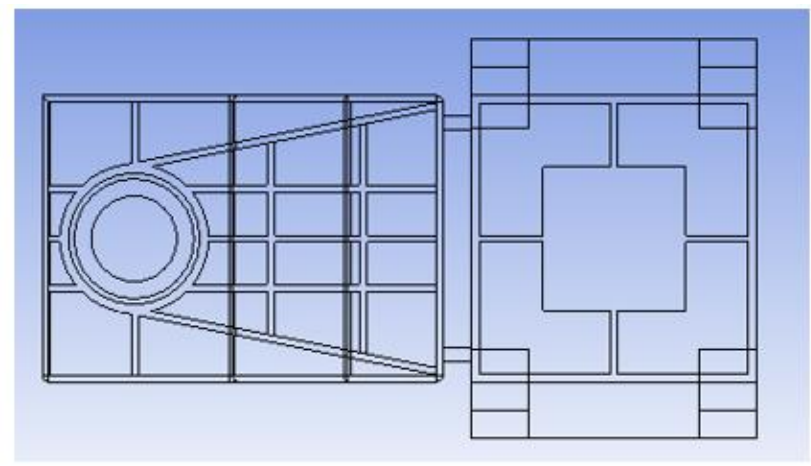

Figure 14. Stiffener arrangements

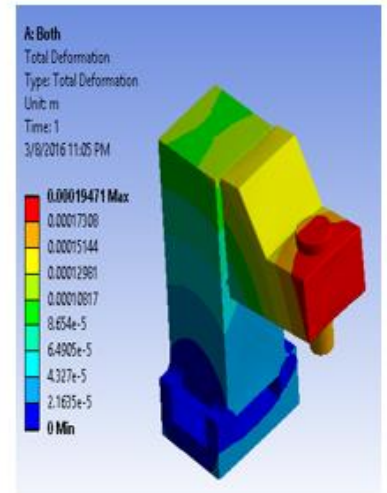

(a)

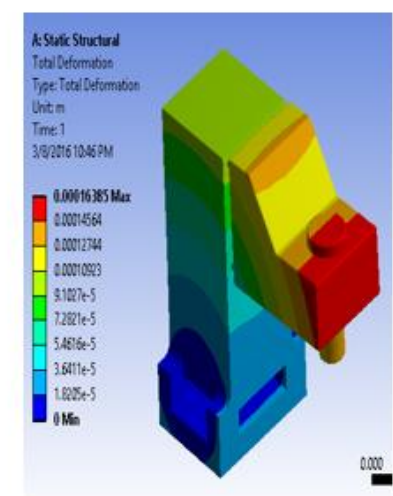

(b)
Figure 15. (a) - Max. Deformation without ribs: 0.00019m (b) - Max. Deformation with ribs: $0.00016 \mathrm{~m}$

\section{Shape optimization}

Shape optimization is part of the field of optimal control theory. The typical problem is to find the shape which is optimal in that it minimizes a certain cost function while satisfying given constraints. In many cases, the functional being solved depends on the solution of a given partial differential equation defined on the variable domain. Shape optimization is a very important part of any design. We can decide the shape of the component using shape optimization. Shape optimization is the process of removing unnecessary material from the component without affecting strength. Sometimes it is necessary to remove material to make pockets or windows in the component for the manufacturing and assembly aspects.

In our shape optimization, the objective function is structural mass, and constraint functions are the structural compliance measure obtained from topology optimization and stress measures [10].

We have used the Shape optimization tool of Ansys workbench for my project.
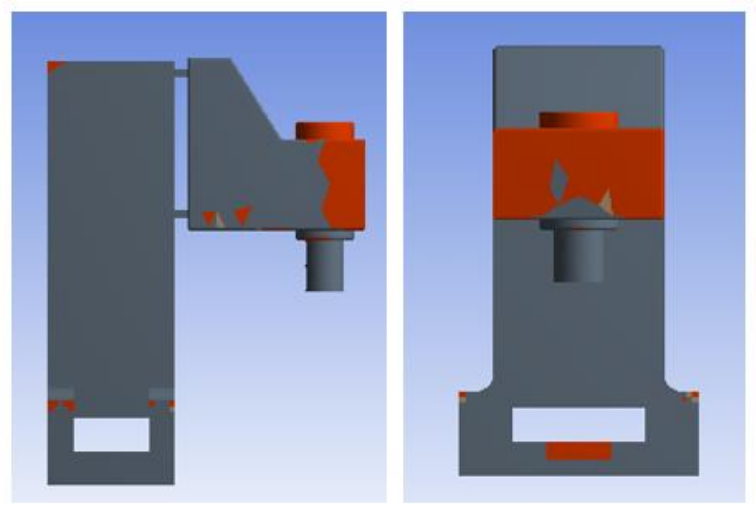

Figure 16. Access structure that can be optimized
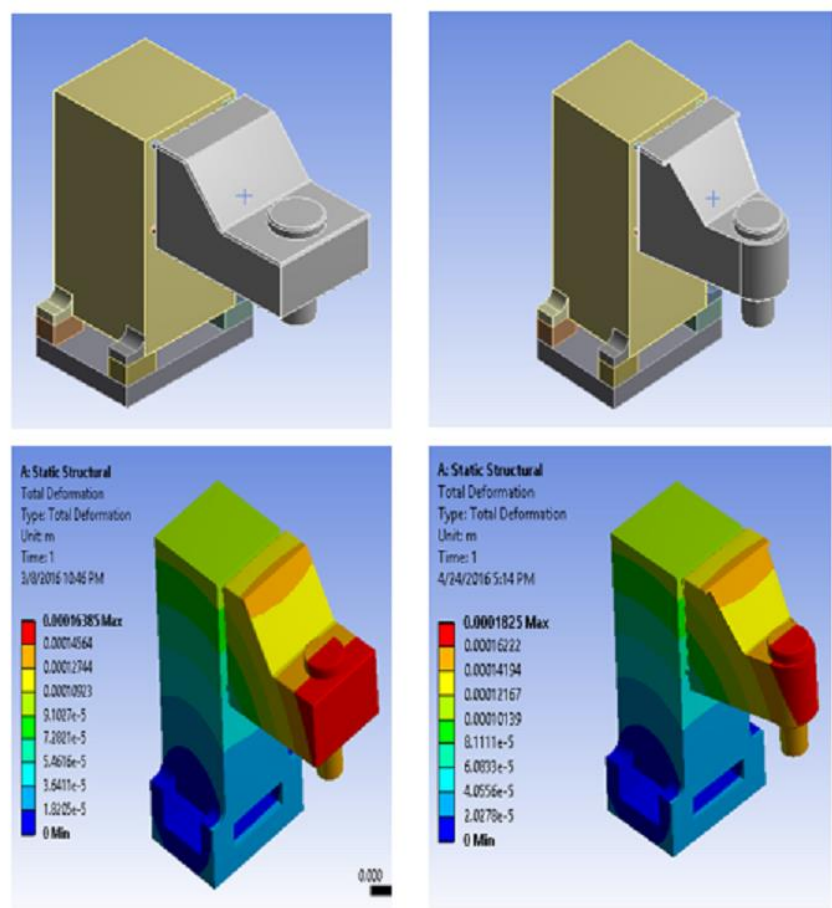

Figure 17. Optimized structure and analysis comparison

\section{Conclusions}

Primary design and structural analysis have been done initially using dimensions of the conventional machine. Later on, various dimensional iterations were analyzed to understand the behavior of the component under different loading conditions. After that with the help of goal-driven optimization, optimum size and mass of column and headstock achieved. Which are within the allowable deformation values.

Results of size optimization of headstock show that mass is reduced by $15 \mathrm{~kg}(6 \%)$, height is reduced by $40 \mathrm{~mm}$ (7\%), and width is reduced by $50 \mathrm{~mm}(9 \%)$.

Results of size optimization of the column show that mass is

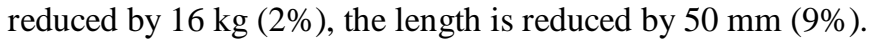
Results of shape optimization of the structure show that mass is reduced by $286 \mathrm{~kg}(19 \%)$. 
By reducing the mass and size significantly, the manufacturing cost of structure can be reduced in a great manner. This may include material cost, machining cost, running cost, etc. A machine can also achieve a higher amount of accuracy because of its lightweight.

The primary advantage of moving the columns instead of the bed is load capacity. We could handle fixtures that weighed several tons, with no issues. Since the load itself is "static", the machine does not have to accelerate or decelerate the load. We had a system where we could be loading or unloading parts and Fixtures while the machine column was Cutting on another section of the bed. Our fixtures were all vacuum-based, and it was easier to plumb the vacuum lines on a fixed bed.

\section{Acknowledgment}

We are sincerely thankful to the Jyoti CNC Automation Ltd. Rajkot For providing all the necessary data of the machine and support.

\section{References}

1. V B Bhandari, "Design of machine element", McGrawHill Publication LTD.

2. L.N. López de Lacalle, "Machine Tools for High Performance Machining", Springer publication.

3. F. KOENIGSBERGER, "DESIGN PRINCIPLES OF METAL-CUTTING MACHINE TOOLS", Pergamon Press, Oxford.

4. N. K. Mehta, "Machine Tool Design", McGraw-Hill Publication LTD.

5. D. Dimitrov, M. Saxer, Productivity Improvement in Tooling Manufacture through High Speed 5 Axis Machining, Procedia CIRP 1 (2012) 277 - 282.
6. Wei-Qin, Design and Analysis of a Small-Scale CostEffective CNC Milling Machine, Thesis Graduate College of the University of Illinois at Urbana-Champaign, 2013.

7. B.V. Subrahmanyam, A. Srinivasan Rao, S.V. Gopala Krishna, CH. Rama Krishna, Static and Dynamic Analysis of Machine Tool Structures, IJRMET Vol. 4, Issue Spl 1, Nov 2013- Apri 12014.

8. Piyush Pandey, Prabhat Kumar Sinha, Vijay Kumar, Manas Tiwari, Process Parametric Optimization of CNC Vertical Milling Machine Using Taguchi Technique in Varying Condition, IOSR Journal of Mechanical and Civil Engineering (IOSR-JMCE), e-ISSN: 2278-1684,p-ISSN: 2320-334X, Volume 6, Issue 5 (May. - Jun. 2013), PP 3442.

9. Mounir Muhammad Koura1, Muhammad Lotfy Zamzam, Amr Ahmed Sayed Shaaban, Virtual System to Simulate the Performance of Various Categories of Machine Tools during the Design Stage, American Journal of Mechanical Engineering, 2015, Vol. 3, No. 1, 7-15.

10. J. Munoa, I. Mancisidor, N. Loix, L.G. Uriarte, R. Barcena, M. Zatarain, Chatter suppression in ram type travelling column milling machines using a biaxial inertial actuator, CIRP Annals - Manufacturing Technology 62 (2013) 407-410.

11. Ahmed A. D. Sarhan, S. R. Besharaty, Javad Akbaria, M. Hamdi, Improvement on a CNC Gantry Machine Structure Design for Higher Machining Speed Capability, International Journal of Mechanical, Aerospace, Industrial, Mechatronic and Manufacturing Engineering Vol:9, No:4, 2015.

12. Neil D. Sims, Vibration absorbers for chatter suppression: A new analytical tuning methodology, Journal of Sound and Vibration 301 (2007) 592-607.

\section{Biographical notes}

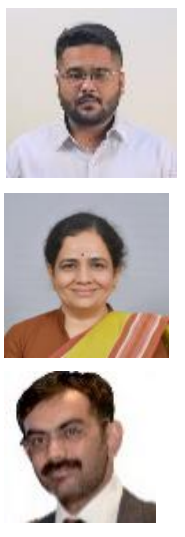

J. J. Vaghela has received his M. Tech in Design Engineering from Nirma University, Ahmedabad, Gujarat in 2016, He is working as an Assistant Professor in the Department of Mechanical Engineering of Darshan Institute of Engineering \& Technology, Rajkot, Gujarat, India. His area of interest includes Machine Design, CAD/CAM \& CAE, and Optimization.

R. R. Trivedi has received her Ph.D. in MEMS from IIT Bombay, Maharashtra in 2016. He is working as an Associate Professor in the Department of Mechanical Engineering of Nirma University, Ahmedabad, Gujarat, India. His area of interest includes MEMS, Optimization, CAD \& CAE.

V. Zala has received his B.Tech in Mechanical Engineering from BVM, VV Nagar, Gujarat. He is working as Executive Head of R \& D Department, Jyoti CNC Automation Ltd. 